\title{
AN INSTRUMENT FOR COMBINED STERNAL BIOPSY AND ASPIRATION
}

\author{
BY \\ L. BERNSTOCK AND H. STERNDALE \\ From the Department of Pathology, Hackney Hospital, London
}

(RECEIVED FOR PUBLICATION MARCH 8, 1951)

It is now universally agreed that examination of bone marrow aspiration material is essential for unravelling many haematological problems. In some cases, however, it is extremely difficult, or even impossible, to obtain specimens, as for example in the myelosclerotic and refractory anaemias. In the former, examination of the bone itself would be of value, and in the latter one would like to see the arrangement of the marrow elements in situ. In the past these difficulties were overcome by subjecting the patient to a minor operation when a bone biopsy was taken.

With the instrument devised by Dameshek (1935), although satisfactory, a small skin incision before taking the biopsy specimen was found essential.

In 1943 Turkel and Bethell produced an instrument which performed a sternal biopsy without the disadvantage of a skin incision and subsequent scarring. The instrument was simple to use and produced a thin core of bone with marrow attached. We have used this needle on several occasions, but found, as did the original authors, that if both biopsy and aspiration material were required a second needle of the usual Sahla pattern had to be inserted as a second operation. Our present modification of this needle, we think, overcomes this disadvantage and now affords a simple method of obtaining both aspiration and biopsy specimens for examination in the one puncture.

\section{The Apparatus}

The apparatus consists of two needles, an outer guiding and aspirating needle, and an inner trephine. The outer needle is built on the general pattern of the Sahla type with an adjustable guard $9 \mathrm{~cm}$. long and a bore of 14 British wire gauge. At one end it has a bevelled cutting end, and is fitted with a stylet. The upper portion of the needle has a fitting to which a syringe with a Luer mounting can be attached.

The inner needle consists of a trephine $11.15 \mathrm{~cm}$. long and a bore of 17 British wire gauge. A metal shoulder, to which are attached metal flanges for ease of handling, is at the upper end. The trephine slips easily into the outer component of the apparatus, extending $0.8 \mathrm{~cm}$., the maximum distance being fixed by the impingement of the metal shoulder on the outer needle head. Its upper portion has a fitting to which a syringe of record pattern can be attached. A long stylet is provided with the trephine which, when in position, extends $0.9 \mathrm{~cm}$. beyond the tip. The sole purpose of the stylet is to help to eject the biopsy. 


\section{Method}

The site selected for this procedure is that for routine sternal marrow aspiration. We normally take a point opposite the second or third ribs, slightly to the left of the mid-line.

Skin, subcutaneous tissue, and periosteum are infiltrated around this point with $2 \%$ procaine.

The outer needle, with stylet in position, is now inserted through the skin. When periosteum is reached the stylet is removed and the needle is adjusted so that it is lying at $75^{\circ}$ with the sternum. The position is maintained with the left hand. The trephine, without its stylet, is now introduced within the outer needle until it reaches periosteum. By a circular boring motion and using only moderate pressure the trephine is sunk up to the metal shoulder. At this point a final twist will finally detach the biopsy from the surrounding structures.

The trephine is removed and handed to an assistant, who, with the aid of the stylet, can express the biopsy into the fixative, which in our cases has been Zenkers fluid.

The stylet of the outer needle is now reintroduced and the procedure is as for a routine aspiration.

Before making films excess blood should be removed from the marrow particles.

The whole of the procedure takes little longer than the accustomed marrow aspiration, causes the patient no greater discomfort, and in many cases affords greater assistance in diagnosis.

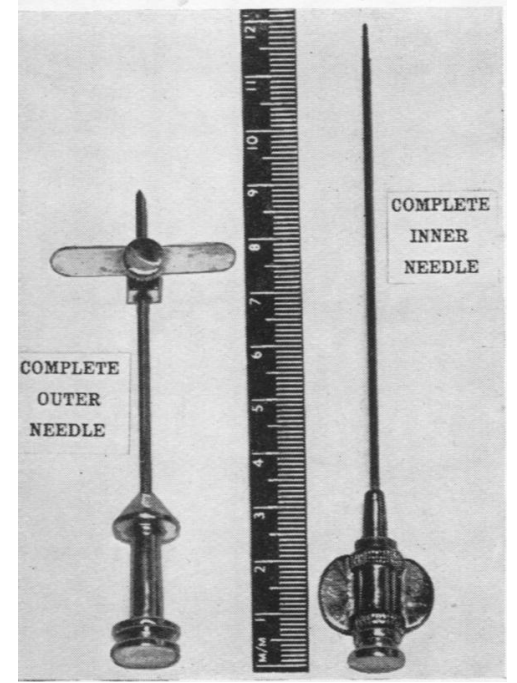

FIG. 1 and 2.-Outer needle and trephine with stylets in situ, and component parts of instrument. 
Our thanks are due to Dr. L. Steingold for his help with the preparation of the histological specimens; to Dr. H. B. May for his helpful criticism; to the Nucleus Photographic Specialists for the photographs; and to Charles Thackray for making the instrument to our specification.

The instrument is now available from Charles Thackray, Ltd., 38, Welbeck Street, London, W.1.

\section{REFERENCES}

Dameshek, W. (1935). Amer. J. med. Sci., 190, 617.

Turkel, H., and Bethell, F. H. (1943). J. Lab. clin. Med., 28, 1246. 